\title{
Indicadores de design sustentável para a valorização do patrimônio histórico, cultural e natural do Maranhão
}

\author{
RESUMO
}

André de Souza Lucca aslucca@yahoo.com.br

Universidade Tecnológica Federal do Paraná (UTFPR), Curitiba, Paraná, Brasil

\begin{abstract}
Baseado nos trabalhos de levantamento bibliográfico narrativo, pesquisa documental e observação direta intensiva, o presente texto apresenta os resultados da pesquisa sobre as estratégias e indicadores de design para a valorização dos recursos e produtos locais no território maranhense. A pesquisa teve como objetivo promover a competitividade e a sustentabilidade das atividades produtivas maranhenses através da valorização do patrimônio local sob a ótica do Design Sustentável. Este trabalho reflete a premissa de que o uso sustentável dos recursos locais pode melhorar a qualidade de vida de grande parte da população envolvida com o extrativismo, a agricultura familiar, a produção de produtos típicos e o turismo no Maranhão. Como resultado, este trabalho estabeleceu indicadores de design para a valorização da cadeia produtiva do babaçu, da produção artesanal com o buriti, da cerâmica artesanal e do patrimônio histórico e natural do Maranhão.
\end{abstract}

PALAVRAS-CHAVE: Design sustentável. Design estratégico. Valorização do patrimônio local. 


\section{INTRODUÇÃO}

Segundo Krucken (2009) para valorizar os recursos e produtos locais é necessário perceber as qualidades do contexto para se compreender as relações que se formam em torno da produção e do consumo destes produtos. Para a autora, os produtos locais envolvem simultaneamente dimensões físicas e cognitivas. Eles são caracterizados por manifestações culturais fortemente relacionadas com o território e são o resultado de uma rede, tecida ao longo do tempo, que envolve os recursos da biodiversidade, os modos tradicionais de produção, os costumes e os hábitos de consumo.

Para que os consumidores reconheçam as qualidades dos produtos locais é necessário comunicá-las com eficiência. Assim, a identidade local transforma-se no ponto de partida para qualquer hipótese de design para o território. Uma identidade que deve ser selecionada entre os diferentes perfis que um território pode exprimir. Esta identidade deve ser reconhecida, renovada ou planificada, para depois ser compartilhada pelos atores locais (PARENTE, 2010).

Nesse contexto, vários autores ressaltam que o papel do designer é aquele de servir de enlace entre as exigências dos usuários e dos produtores, de promover sinergias entre as atividades produtivas no território, de facilitar os processos colaborativos e de mediar as diversas disciplinas envolvidas com o processo projetual (DE GIORGI; GERMAK, 2008; THACKARA, 2008; MANZINI, 2008; BISTAGNINO, 2009; VEZZOLI, 2010).

Neste texto são apresentados os resultados relativos à valorização do patrimônio histórico, cultural e natural do Maranhão obtidos com a pesquisa intitulada: Estratégias e indicadores para projetos de valorização de recursos e produtos no território maranhense, desenvolvida durante o período de agosto de 2014 a agosto de 2016 e que contou com o auxílio da Fundação de Amparo à Pesquisa e ao Desenvolvimento Científico e Tecnológico do Maranhão - FAPEMA1.

\section{METODOLOGIA}

A pesquisa foi caracterizada por uma abordagem qualitativa uma vez que foram empregados instrumentos não estruturados para coleta de dados, como o 
levantamento bibliográfico narrativo, a pesquisa documental e a observação direta intensiva.

Tal abordagem permitiu aprofundar o entendimento dos conceitos do design sustentável relacionados com a valorização de recursos e produtos locais e, em particular, identificar as estratégias de design coerentes com o contexto maranhense. Os instrumentos de pesquisa foram utilizados sequencialmente durante as três principais etapas do desenvolvimento do trabalho, conforme a Figura 1.

Figura 1 - Etapas do desenvolvimento da pesquisa

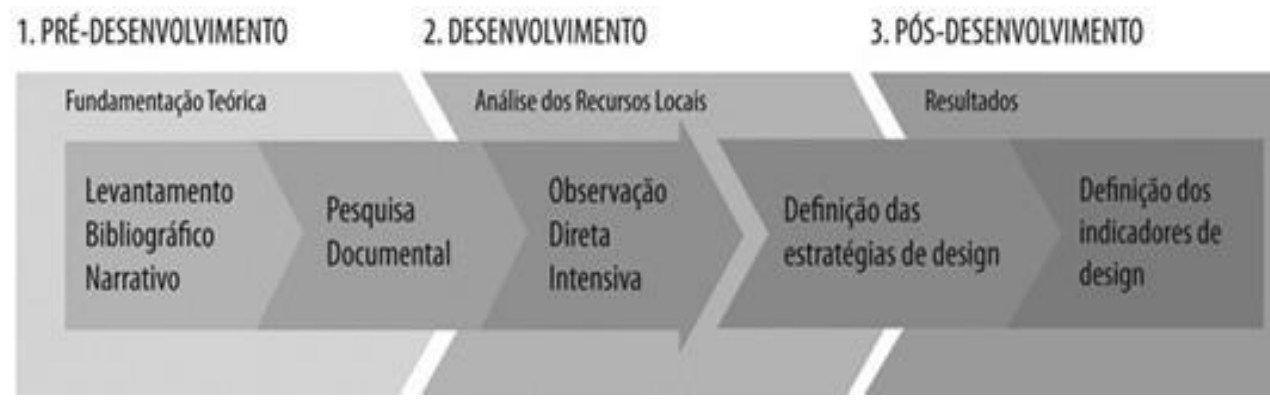

Fonte: Autoria própria (2017).

A fundamentação teórica da pesquisa foi efetuada através do levantamento bibliográfico narrativo. Com este instrumento se procurou entender o estado da arte sobre os princípios de design relacionados com a sustentabilidade e a valorização dos recursos e produtos locais a partir de pesquisas recentes em nível de mestrado e doutorado realizadas nos Programas de Pós-graduação em Design no Brasil e em publicações científicas das áreas da Economia Ecológica, do Desenvolvimento Local, da Agricultura Ecológica e do Ecoturismo.

Segundo Rocha (1999 apud VOSGERAU; ROMANOWSKI, 2014) o levantamento bibliográfico narrativo é um estudo que tem por característica permitir estabelecer relações com produções bibliográficas anteriores, identificando temáticas recorrentes e apontando novas perspectivas.

A pesquisa documental é um instrumento de pesquisa similar ao levantamento bibliográfico, diferenciando-se pela natureza das fontes consultadas. Segundo Gil (2002) enquanto que o levantamento bibliográfico utiliza, fundamentalmente, as contribuições acadêmicas dos diversos autores sobre determinado assunto, a pesquisa documental se vale de materiais que não 
receberam, ainda, um tratamento analítico, ou que podem ser reelaborados de acordo com os objetos da pesquisa, como documentos em vídeo, jornais, comunicações empresariais, entre outros.

Neste trabalho a pesquisa documental contribuiu na escolha dos recursos e produtos a serem analisados a partir do estudo das características e do panorama da economia maranhense através da análise de relatórios e documentos publicados por órgãos como a Empresa Brasileira de Pesquisa Agropecuária - EMBRAPA, Instituto Chico Mendes de Conservação da Biodiversidade - ICMBio, Secretaria de Agricultura Pecuária e Pesca do Maranhão, associações, cooperativas e indústrias locais.

A etapa de desenvolvimento da pesquisa foi baseada na observação direta intensiva e num novo levantamento bibliográfico narrativo onde foram analisadas pesquisas acadêmicas que abordam, especificamente, assuntos relacionados com o patrimônio histórico, cultural e natural do Maranhão. Esta etapa contribuiu com dados sobre o centro histórico de São Luís, a produção da cerâmica artesanal da comunidade de Itamatatiua, o trabalho artesanal com o buriti maranhense e o Polo turístico do Parque Nacional dos Lençóis Maranhenses. A observação direta intensiva possibilitou o estudo das características e potencialidades da cadeia produtiva do babaçu no município de Itapecuru Mirim. A escolha da cadeia produtiva do babaçu como objeto para a observação intensiva se justifica dada a grande importância desta atividade para a economia do estado.

Segundo Gil (2008) apesar de ser caracterizada como espontânea e informal, a observação se coloca num plano científico, pois vai além da simples constatação dos fatos. Nela é possível perceber alguns itens, que em virtude de serem significativos, são demandados pelos pesquisadores, como os sujeitos envolvidos, quem são os participantes, qual é o cenário, onde as pessoas se situam, quais são as características locais, os comportamentos sociais, o que realmente ocorre em termos sociais, como as pessoas se relacionam, de que modo o fazem e que linguagens utilizam.

$\mathrm{Na}$ etapa de pós-desenvolvimento do trabalho foram gerados os resultados da pesquisa que se traduziram em indicadores de design sustentável orientados para a valorização do patrimônio histórico, cultural e natural do Maranhão, bem como, na definição de diretrizes específicas de projeto para a valorização do centro histórico de São Luís, da cerâmica artesanal maranhense, da 
cadeia produtiva do babaçu maranhense, da produção artesanal com o buriti no Maranhão e do Polo turístico do Parque Nacional dos Lençóis Maranhenses.

\section{DESENVOLVIMENTO}

\section{O CENTRO HISTÓRICO DE SÃO LUÍS, PATRIMÔNIO MUNDIAL DA UNESCO}

Conforme descreve Souza (2014) em sua pesquisa, a ilha de Upaon-Açu, onde a capital do estado do Maranhão se encontra, foi descoberta em 1535 pelos franceses que ali fundaram em 1612 a cidade de São Luís. O nome de batismo da cidade prestava homenagem simultaneamente a Luís IX, rei da França e santo da Igreja Católica, e Luís XIII, rei da França no período da fundação da cidade. Era a tentativa de se criar no Brasil a França Equinocial. Os portugueses retomaram a região somente em 1615 .

São Luís tem características portuguesas muito acentuadas como a construção em planta ortogonal e fundação a partir do antigo forte militar que foi a primeira edificação da cidade.

A área de fundação da cidade em 1612, cujo traçado é creditado ao Engenheiro-militar Francisco Frias de Mesquita, viu o seu desenvolvimento se acentuar com a criação do monopólio da Companhia Geral do Comércio do GrãoPará e Maranhão (1755-1778). Concomitante ao funcionamento desta Companhia, e de um considerável desenvolvimento econômico de São Luís, há a reconstrução da Baixa Pombalina em Lisboa. Nesta época, com os contatos frequentes entre as duas cidades, as técnicas construtivas e os materiais de construção utilizados em São Luís foram influenciados por aqueles utilizados na metrópole portuguesa (LEITE; RAMOS, 2013 apud SOUZA, 2014).

A urbanização de São Luís acompanhou o desenvolvimento dos ciclos econômicos que floresceram e decaíram no Maranhão. No século XIX tem-se o apogeu do ciclo agroexportador do algodão. A cana-de-açúcar teve o seu ciclo entre 1868 e 1894. Com a proclamação da República e a abolição da escravatura, desorganiza-se a estrutura econômica local e inicia-se um período de decadência. No final do século XIX a elite econômica local promove uma forte iniciativa em direção à industrialização com a construção de um parque industrial têxtil. Entretanto, este desenvolvimento começa a declinar já no primeiro decênio do século XX. É neste momento que se inicia o abandono dos casarões históricos com 
o deslocamento das famílias mais abastadas para as novas regiões residenciais da cidade. Muitos autores creditam a este fato a ocorrência de uma certa conservação do centro com o congelamento da área histórica e do seu traçado original (LEITE; RAMOS, 2013; LACROIX, 2000; LOPES, 2008; MEIRELES, 2001 apud SOUZA, 2014).

O processo de tombamento do centro histórico de São Luís pela Organização das Nações Unidas para a Educação, a Ciência e a Cultura - UNESCO, teve início na década de 1970 com a elaboração de um minucioso conjunto de diretrizes para a preservação das cidades de São Luís e Alcântara. Este documento se tornaria a referência para a preservação dos conjuntos arquitetônicos coloniais, identificando as origens da arquitetura a partir dos modelos Barrocos-Pombalinos utilizados no processo de reconstrução de Lisboa após o terremoto de 1755 (ANDRÈS, 1998; ESPÍRITO SANTO, 2006 apud SOUZA, 2014).

O centro histórico de São Luís obteve a recomendação para a sua inscrição na Lista do Patrimônio Mundial em 1997, considerando o núcleo original da cidade e dos quarteirões que o circundam. O Conselho Internacional dos Monumentos e Sítios, em seu parecer, enfatizou o excepcional valor de São Luís como exemplo de cidade colonial portuguesa, com traçado conservado e conjunto arquitetônico representativo, assim como o diferencial caracterizado pela utilização de refinados azulejos portugueses para cobertura das fachadas das casas e sobrados, seja por fins decorativos, ou como isolante térmico, adequandose às condições climáticas desta região equatorial brasileira (SOUZA, 2014).

Atualmente, a conservação dos casarões é um grande desafio para a comunidade, poder público e moradores. Inúmeras construções estão em estado crítico, inclusive, na área de tombamento pelo Patrimônio Mundial da UNESCO.

\section{A CERÂMICA ARTESANAL DE ITAMATATIUA, EXPRESSÃO DA CULTURA MARANHENSE}

Itamatatiua é uma comunidade remanescente dos quilombos localizada às margens da rodovia MA-106 próxima ao município de Alcântara. Em sua pesquisa Cestari (2014) relata que essa comunidade possui uma economia baseada na agricultura e pecuária de subsistência, pesca, pequenos comércios e na produção de artefatos cerâmicos.

Segundo a autora, dois momentos foram muito importantes para o desenvolvimento da cerâmica local. Inicialmente o ofício se orientava apenas aos 
serviços do empreendimento da Ordem Carmelita, período em que eram produzidos artefatos para construção como tijolos e telhas. Posteriormente, passou-se a produzir também utilitários para suprir as suas próprias necessidades.

Para Pereira Júnior (2011 apud RIBEIRO, 2014) a comunidade de Itamatatiua ao longo de sua história desenvolveu uma estreita relação com a cerâmica. Ela está presente no espaço doméstico de todos os moradores da comunidade, nas festividades, reuniões e rituais religiosos.

Ainda segundo o autor, o trabalho artesanal em Itamatatiua é exclusivo das mulheres. Cada artesã tem seu próprio modo de fazer a cerâmica. Assim, observa-se uma grande variedade nas formas relacionada ao aprimoramento individual da técnica que diferencia as peças das artesãs entre si. Apesar disso, os laços de parentesco entre as artesãs e as fortes relações sociais da comunidade possibilitam a disseminação dos saberes relacionados ao ofício ceramista. As artesãs se reúnem para produzir potes, panelas, xícaras e esculturas figurativas. A participação do homem é limitada aos processos de queima, transporte, venda e produção de materiais voltados à construção.

Para Cestari (2014) o pote de Itamatatiua é historicamente o utilitário de maior representatividade na produção local. Por séculos tinha função objetiva de transportar e armazenar água, no entanto, com as mudanças na infraestrutura da comunidade, como a chegada da água encanada e dos modernos produtos em alumínio e plástico, este artefato perdeu a sua utilidade prática chegando ao desuso.

Segundo Noronha (2012 apud CESTARI, 2014) a partir da década de 1990 o pote é resgatado como símbolo de identidade local através de projetos de intervenção que visavam a manutenção do artesanato local. A modelagem das peças ainda é feita manualmente seguindo a técnica de união de rolos. A confecção de bonecas em cerâmica também tem grande importância. As personagens retratadas estão relacionadas com as festas, as danças típicas, a religiosidade, as cenas do cotidiano e aos próprios personagens da localidade.

\section{O BABAÇU, PATRIMÔNIO NATURAL E CULTURAL DO MARANHÃO}

Segundo Frazão (2002) a denominação babaçu se refere ao fruto obtido de uma palmácea da família Arecaceae e também da própria palmeira do gênero 
Orbignya que cobre cerca de $37 \%$ do território maranhense. De acordo com o Instituto Brasileiro de Geografia e Estatística - IBGE (2012) o Maranhão é o principal extrator da amêndoa do babaçu, sendo responsável por mais de $90 \%$ da produção no Brasil.

O babaçu maranhense destaca-se não só por sua importância na geração de empregos e renda, mas também por sua relevância social e ambiental vinculada à manutenção dos costumes e saberes ligados ao extrativismo vegetal, a criação de condições para a permanência da população em seus municípios de origem e a preservação dos babaçuais que vêm sendo substituídos por áreas de pasto (VIEGAS, 2015).

Segundo Carrazza, Silva e Avila (2012) o fruto do babaçu é o principal produto extraído da palmeira. A palmeira frutifica a partir do oitavo ano de vida e alcança a produção plena após 15 anos. Cada safra pode ter entre 3 e 5 cachos e cada cacho pode produzir de 300 a 500 frutos.

A palmeira como um todo pode ser beneficiada desde o caule até o fruto e suas aplicações variam da geração de energia passando por uma gama de produtos alimentícios, de beleza e de limpeza. Na Tabela 1 estão descritos os principais produtos que podem ser obtidos a partir do babaçu.

Tabela 1 - Principais produtos obtidos a partir do babaçu

$\begin{array}{ll}\text { Talo das folhas } & \begin{array}{l}\text { Estrutura para paredes e cercas, materiais para artesanato em } \\ \text { geral }\end{array} \\ \text { Palha das folhas } & \begin{array}{l}\text { Cobertura para casas, material para cestaria artesanal } \\ \text { Xaxim, estofado para banco de veículos, queima, embalagens, } \\ \text { Epicarpo do fruto }\end{array} \\ \text { Mesocarpo do fruto } & \begin{array}{l}\text { Farinha rica em amido, aglomerante para fabricação de } \\ \text { briquetes } \\ \text { Carvão, material para artesanato em geral }\end{array} \\ \text { Endocarpo do fruto } & \begin{array}{l}\text { Alimentação (óleo, leite, amêndoa in natura), cosméticos e } \\ \text { produtos de limpeza } \\ \text { Amêndoa }\end{array} \\ \text { Alimentação (palmito e vinho) } \\ \text { Caule jovem }\end{array}$

Fonte: Autoria própria adaptado de Pinto et al. (2010).

O beneficiamento do fruto do babaçu pode produzir mais de 64 subprodutos, dentre os quais se destacam o etanol, o metanol, fertilizantes, carvão ativado, amido, acetatos, óleo, sabão e glicerina (PORTO, 2004).

Segundo Viegas (2015) no Maranhão as comunidades extrativistas do 
babaçu pouco se beneficiam desse potencial. O epicarpo, endocarpo e mesocarpo muitas vezes são destinados apenas para a produção de carvão. A amêndoa, por ter maior valor econômico, é beneficiada apenas para a retirada do óleo e o resíduo deste processo é utilizado para ração animal.

De acordo com Porto (2004) a grande dificuldade na industrialização do babaçu no Maranhão se deve às precárias condições de trabalho, exclusivamente manual, para a extração e quebra do fruto. O autor ressalta que, desde a década de 1950, os setores público e privado têm investido no processo de industrialização, mas sem resultados financeiros compensatórios.

Para o Ministério do Meio Ambiente do Brasil - MMA (2009) a economia babaçueira atingiu seu ponto alto entre as décadas de 1960 e 1980. Existiam 52 empresas de médio e grande porte no Maranhão que produziam óleo bruto e refinado para as indústrias alimentícias e de higiene e limpeza no país e no exterior. Neste período o babaçu foi o principal item de exportação do estado.

Entretanto, com o avanço da produção da soja no Brasil na década de 1980, o mercado de óleo de babaçu destinado para a indústria alimentícia reduziu-se de forma significativa. Além disso, a abertura da economia brasileira e a concorrência com outros óleos, como o óleo de palma, gerou a falência de várias empresas (DESER, 2007).

Pinto et al. (2010) estima que pelo menos 300 mil famílias agroextrativistas são economicamente dependentes do babaçu no Maranhão. Mesmo com o parque industrial em decadência o estado ainda é o maior produtor de óleo de babaçu no Brasil (VIEGAS, 2015).

\section{O ARTESANATO COM O BURITI, EXPRESSÃO DA CULTURA MARANHENSE}

O buriti (Mauritia vinifera Martius) é uma das maiores espécies de palmeiras do Brasil e está presente em grande parte do território nacional, sendo abundante na Região Norte e Nordeste (LORENZI, 2002 apud GUIMARÃES, 2014).

Segundo o Instituto Sociedade População e Natureza - ISPN (2008 apud GUIMARÃES, 2014) muitos naturalistas estrangeiros incluem o buriti no grupo das árvores da vida. Suas folhas são utilizadas para cobrir casas, das espigas se extrai um líquido doce de coloração rosa que, ao fermentar, se transforma em bebida alcoólica, a medula do tronco fornece uma fécula chamada ipurana, do broto é 
possível retirar o palmito, as raízes possuem qualidades medicinais e a polpa dos frutos é utilizada para confecção de doces, sucos e licores.

Em sua pesquisa Guimarães (2014) ressalta também que o buriti se comporta com uma rica matéria-prima para o artesanato. No Maranhão são produzidas muitas peças com as palhas do buriti. $\mathrm{O}$ talo mais duro serve para se fazer cestas e cabos de vassoura, as tiras mais grossas são usadas na fabricação de tapetes e esteiras e, com as mais finas, bolsas, peneiras, toalhas de mesa, brinquedos e chapéus. Porém, é no trabalho artesanal que o buriti tem alcançado maior destaque. Este utiliza o linho extraído das folhas jovens, chamado seda do buriti, com a qual as artesãs locais fazem peças mais delicadas utilizando técnicas de tecelagem manual como crochê, macramê e ponto batido.

\section{O PARQUE NACIONAL DOS LENÇÓIS MARANHENSES, PATRIMÔNIO NATURAL DO BRASIL}

De acordo com Martins (2008) até a segunda metade da década de 1990 o Maranhão era considerado distante e muitas vezes inacessível para os turistas das demais regiões do Brasil. A partir de 1997, com o tombamento do Centro Histórico de São Luís, o poder público começou a tomar medidas de incentivo ao turismo no estado. Assim, tem-se o Plano Integrado para o Desenvolvimento do Turismo, implementado em 2000, como estratégia para incentivar o turismo ecológico e cultural considerados a vocação do estado.

Este plano definiu cinco polos2 receptores com o propósito de explorar a diversidade dos ecossistemas existentes no estado. Segundo Silva (2008 apud MARTINS, 2008) devido à singularidade paisagística existente no Parque Nacional dos Lençóis Maranhenses, as ações de desenvolvimento acabaram se concentrando no incremento daquela região.

Os Lençóis Maranhenses são uma manifestação geomorfológica de 155 mil hectares da planície costeira do estado do Maranhão que possui o maior registro de sedimentação eólica do quaternário da América do Sul, correspondendo a campos de dunas livres e fixas que juntos alcançam larguras de até $50 \mathrm{~km}$ (GONÇALVES et al., 2003 apud MARTINS, 2008).

Segundo Tsuji (2002 apud MARTINS, 2008) até fins da década de 1990 a

2 O Polo São Luís - Alcântara, o Polo dos Lençóis Maranhenses, o Polo da Floresta dos Guarás, o Polo do Delta das Américas e o Polo da Chapada das Mesas. 
região era considerada por seus moradores apenas como um deserto, cujas areias era motivo de pesar pois não cooperavam com a economia local que era pautada, em sua maioria, na subsistência com o cultivo de mandioca, arroz, algodão, pesca e criação de animais de pequeno porte, além da extração da castanha de caju.

A região apresenta a combinação de elementos característicos de áreas litorâneas, com praias, dunas e mangues intocados, e sol na maior parte do ano. Além dos serviços turísticos, as principais atividades econômicas nas comunidades circunvizinhas ao parque são a pesca artesanal e a fiação de palhas de buriti.

\section{INDICADORES DE DESIGN SUSTENTÁVEL PARA A VALORIZAÇÃO PARA A VALORIZAÇÃO DO PATRIMÔNIO HISTÓRICO, CULTURAL E NATURAL DO MARANHÃO}

Os indicadores são sinais tipicamente mensuráveis que podem refletir uma característica quantitativa ou qualitativa, de importância vital para que se possa fazer julgamentos sobre as condições de um determinado sistema. Os indicadores provêm, assim, informação essencial sobre um sistema, facilitando a orientação e a tomada de decisão em um mundo complexo (HODGE et al., 1999; PINTER et al., 2000; BOSSEL, 1999 apud SOUZA, 2007).

Para um melhor entendimento os indicadores propostos neste trabalho foram estabelecidos a partir dos níveis de tomada de decisão da gestão do design, conforme a Figura 2. Os indicadores estratégicos (IE) e táticos (IT) aqui apresentados têm um caráter panorâmico e possuem o objetivo de auxiliar os designers na definição de suas intenções projetuais e do metaprojeto3. Já os indicadores operacionais $(\mathrm{IO})$ se referem diretamente às diretrizes de projeto (DP) para a valorização dos recursos locais analisados.

Figura 2 - Objetivos dos indicadores propostos neste trabalho

\begin{tabular}{|c|c|c|}
\hline NIVELL ESTRATÉGICO & NIVEL TÁTICO & NIVEL OPERACIONAL \\
\hline $\begin{array}{l}\text { Os indicadores estratégicos (IE) } \\
\text { desenvolvem uma visão estratégica } \\
\text { alinhada com o desenvolvimento } \\
\text { local sustentável }\end{array}$ & $\begin{array}{l}\text { Os indicadores táticos (IT) orien- } \\
\text { tam o planejamento dos projetos } \\
\text { (metaprojeto) a partir dos princi- } \\
\text { pios do design sustentável }\end{array}$ & $\begin{array}{l}\text { Os indicadores operacionais (I0) } \\
\text { expressam as diretrizes de pro- } \\
\text { jeto (DP) para a valorizaçăo dos } \\
\text { recursos locais analisados }\end{array}$ \\
\hline
\end{tabular}

Fonte: Autoria própria baseado em Mozota et al. (2011).

${ }^{3}$ Veja: DE MORAES, D. Metaprojeto: o design do design. São Paulo: Blucher, 2010; DESERTI, A. Metaprogetto. Riflessioni teoriche ed esperienze didattiche. Milão: Poli.Design, 2003; COLLINA, L. Design e metaprogetto. Teorie, strumenti, pratiche. Milão: Poli.Design, 2003. 
A leitura destes indicadores a partir dos níveis estratégico, tático e operacional permite que haja o encadeamento dos propósitos do projeto, conforme a Figura 3, auxiliando os designers na manutenção da direção estratégica programada e facilitando a análise da viabilidade das ações de projeto pretendidas.

Figura 3 - Indicadores de design sustentável para a valorização do patrimônio histórico, cultural e natural do Maranhão

\begin{tabular}{|c|c|c|}
\hline INDICADORESESTRATÉGICOS & INDICADORESTÁTICOS & INDICADORES OPERACIONAIS \\
\hline $\begin{array}{l}\text { - Buscar a inovaçăo radical } \\
\text { sustentável (IE-1) }\end{array}$ & \multirow{2}{*}{$\begin{array}{l}\text { - Estabelecer os projetos a partir } \\
\text { dos princípios do Design Social- } \\
\text { mente Responsável (IT1) }\end{array}$} & $\begin{array}{l}\text { - Diretrizes de projeto para a } \\
\text { valorização do centro histórico de }\end{array}$ \\
\hline - Promover estilos de vida & & São Luis (DP1) \\
\hline sustentáveis (IE2) & \multirow{2}{*}{$\begin{array}{l}\text { - Estabelecer os projetos a partir } \\
\text { dos princípios do Design para } 0 \\
\text { Território (IT2) }\end{array}$} & - Diretrizes de projeto para a va- \\
\hline $\begin{array}{l}\text { - Promover a ecoeficiência } \\
\text { sistêmica através da integração }\end{array}$ & & $\begin{array}{l}\text { lorizaçao da ceramica artesanal } \\
\text { maranhense (DP2) }\end{array}$ \\
\hline de empresas (IE3) & \multirow{2}{*}{$\begin{array}{l}\text { - Proporcionar a integração dos } \\
\text { projetos com as organizações } \\
\text { colaborativas locais (IT3) }\end{array}$} & - Diretrizes de projeto para a \\
\hline $\begin{array}{l}\text { - Promover a responsabilidade } \\
\text { social (IE4) }\end{array}$ & & $\begin{array}{l}\text { valorizaçao da cadela produtiva } \\
\text { do babaçu maranhense (DP3) }\end{array}$ \\
\hline $\begin{array}{l}\text { - Apoiar empreendimentos } \\
\text { colaborativos (IES) }\end{array}$ & $\begin{array}{l}\text { - Conceber os projetos como um } \\
\text { processo de Co-design (IT4) }\end{array}$ & - Diretrizes de projeto para a va- \\
\hline - Promover o reconhecimento e & $\begin{array}{l}\text { - Projetar a partir das identidades } \\
\text { locais (IT5) }\end{array}$ & - Diretrizes de projeto para a \\
\hline cultura local (IEG) & \multirow{2}{*}{$\begin{array}{l}\text { - Aprimorar e desenvolver os } \\
\text { produtos típicos locais (IT6) }\end{array}$} & $\begin{array}{l}\text { valorizaçăo do Polo turístico do } \\
\text { Parque Nacional dos Lencóis }\end{array}$ \\
\hline - Fortalecer, preservar e promo- & & Maranhenses (DP5) \\
\hline $\begin{array}{l}\text { ver os produtos vernaculares, } \\
\text { artesanais e tipicos (IE7) }\end{array}$ & \multirow[t]{2}{*}{$\begin{array}{l}\text { - Promover a certificação dos } \\
\text { produtos de origem (IT7) }\end{array}$} & \\
\hline $\begin{array}{l}\text { - Apoiar a construção de arranjos } \\
\text { produtivos locais (IE8) }\end{array}$ & & \\
\hline
\end{tabular}

Fonte: Autoria própria baseado em Manzini e Vezzoli (2008), Manzini (2008), Krucken (2009), Vezzoli (2010), Santos et al. (2011).

Ao confrontar estes indicadores com o contexto no qual os recursos estudados estão inseridos, foi possível propor diretrizes específicas de projeto para a valorização do centro histórico de São Luís (DP1), da cerâmica artesanal maranhense (DP2), da cadeia produtiva do babaçu maranhense (DP3), da produção artesanal com o buriti maranhense (DP4) e do Polo turístico do Parque Nacional dos Lençóis Maranhenses (DP5), conforme a Tabela 2 e seguintes.

Tabela 2 - Diretrizes para a valorização do centro histórico de São Luís (DP1)

\begin{tabular}{lll}
\multicolumn{1}{c}{ Diretriz } & \multicolumn{1}{c}{ Descrição } & \multicolumn{1}{c}{$\begin{array}{l}\text { Indicadores } \\
\text { relacionados }\end{array}$} \\
$\begin{array}{ll}\text { Desenvolver e } \\
\text { promover a }\end{array}$ & $\begin{array}{l}\text { Estabelecer um maior intercâmbio e integração } \\
\text { entre a população local e os visitantes, tendo }\end{array}$ & $\begin{array}{l}\text { IE6/IT2/IT3/IT } \\
\text { identidade cultural } \\
\text { maranhense }\end{array}$ \\
& $\begin{array}{l}\text { como pano de fundo o patrimônio cultural local. } \\
\text { Promover um contínuo processo de } \\
\text { reconstrução e redescoberta de identidade local }\end{array}$
\end{tabular}




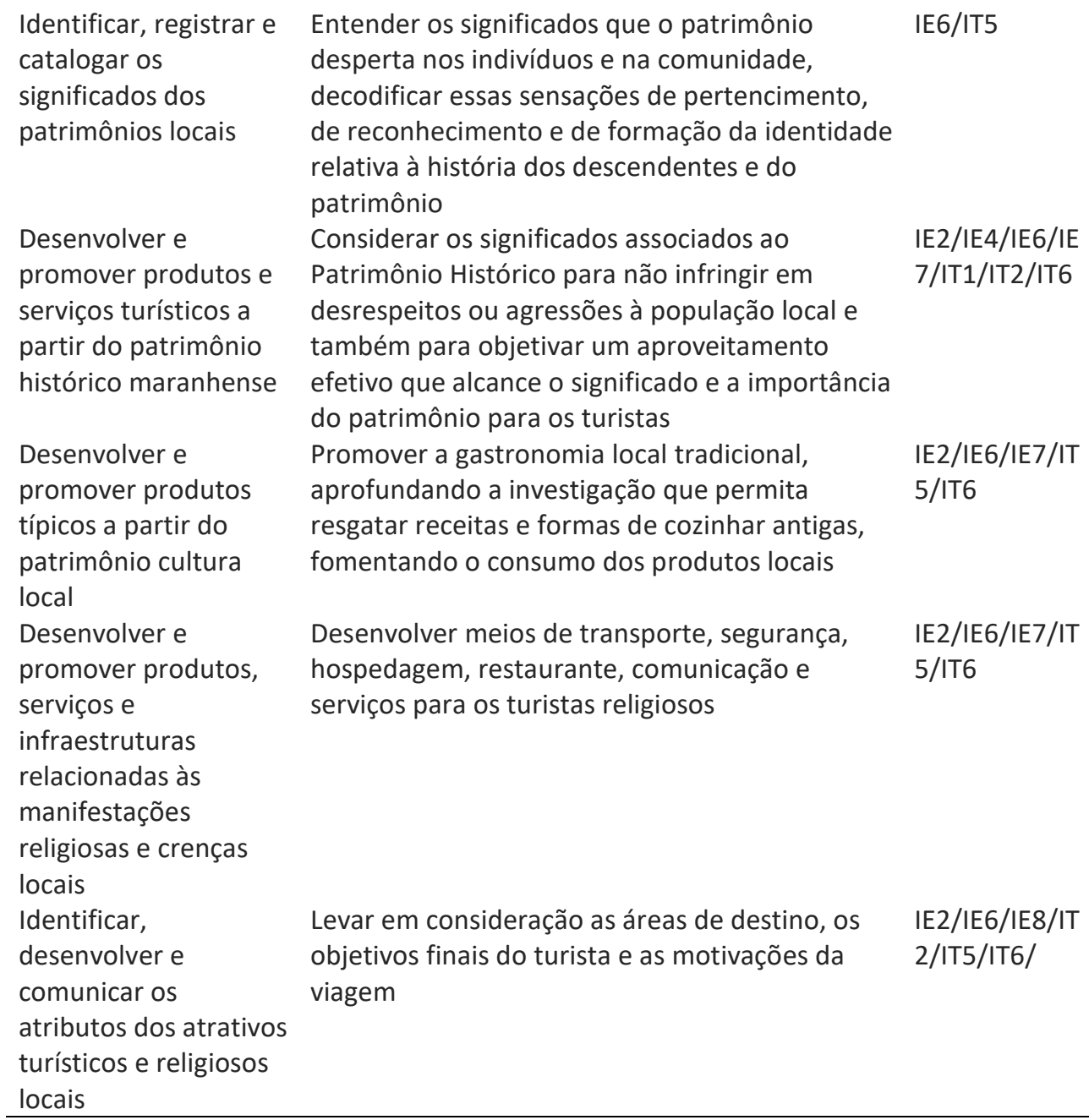

Fonte: Autoria própria baseado em Trevisan (2006) e Oliveira (2009).

A partir do estudo das características e potencialidades da cerâmica artesanal de Itamatatiua, no município de Alcântara - MA, foi possível organizar um conjunto de diretrizes de projeto específicas para valorizar a cerâmica artesanal maranhense (DP2), conforme o Tabela 3. 
Tabela 3 - Diretrizes para a valorização da cerâmica artesanal maranhense (DP2)

Diretriz
Desenvolver e
valorizar a identidade
dos produtos
cerâmicos
maranhenses

Construir marcas para os produtos cerâmicos maranhenses

Promover

intervenções

diretamente nos

produtos cerâmicos

Promover a melhoria das condições técnicas da produção artesanal Potencializar as matérias-primas locais controle do processo de produção artesanal

Apoiar o saber e as práticas tradicionais

Contribuir para valorização e aperfeiçoamento da prática artesanal, mediante organização da produção e comunicação do produto
Descrição

Atribuir aos produtos cerâmicos artesanais

maranhenses uma clara identidade baseada nos

lugares onde são produzidos. Catalogar as

memórias dos grupos e comunidades artesanais, resgatar as técnicas, processos e estilos que existiram como práticas comuns aos ancestrais dos povoados maranhenses. Elaborar embalagens adequadas, selos de origem, rótulos ou etiquetas que contextualizam o produto cerâmico e apresentem a sua história Elaborar identidades visuais e estratégias

Indicadores relacionados

IE6/IE7/IT2/IT

$5 /$ IT6 específicas para a comunicação dos produtos

cerâmicos maranhenses que já possuem uma

IE6/IE8/IT2/IT 5/IT6/

IT7

identidade e qualidade reconhecida, propiciando a comunicação dos valores intangíveis dos artefatos, informando ao consumidor a procedência, as técnicas de produção e ressaltando as tradições e o folclore relacionados

Identificar e atender as demandas específicas do

IE3/IE5/IT1/IT mercado local, respeitando as características do processo de produção da cerâmica local e $3 / \mathrm{IT} 4 /$ IT6 preservando os elementos de referência cultural local

Desenvolver critérios de qualidade para a

IE7/IE8/IT6

produção artesanal relacionadas ao acabamento das peças cerâmicas

Estudar as potencialidades das matérias-primas

locais permitido o planejamento de seu uso,

IE1/IE3/IT2/IT

6

visando a redução do extrativismo desordenado, melhor uso e o aproveitamento dos resíduos

Estudar as técnicas de transformação dos produtos artesanais cerâmicos possibilitando

IE3/IE5/IE8/IT 2/IT3/

IT6

condições de transporte

Identificar e analisar a viabilidade técnica e

ambiental da prática e do uso dos materiais

IE6/IE8/IT2/IT

locais relacionados à extração da argila,

racionalização da matéria prima utilizada na produção, queima dos artefatos cerâmicos, restauração e reutilização das peças cerâmicas quebradas após a queima

Implementar projetos para consolidação de redes que favoreçam, além do incremento da infraestrutura, a incorporação de novas tecnologias para a formação das novas gerações de ceramistas maranhenses 
Promover conexões com áreas afins

Fortalecer redes sociais para aproximar produtores e consumidores Incentivar a formação de redes envolvendo diversos produtores de diferentes origens

Desenvolver e valorizar a identidade dos produtos cerâmicos maranhenses
Desenvolver ferramentas e redes que permitam uma maior interação dos artesãos locais com designers, estilistas, decoradores, arquitetos e empresas do setor imobiliário. Essas conexões podem gerar novas ocupações e fonte de renda para os ceramistas maranhenses Intervir junto aos atores locais envolvidos para a modernização dos espaços, ferramentas de produção dos produtos cerâmicos e das formas para a sua comercialização e comunicação Promover e facilitar o acesso dos ceramistas maranhenses às ações e políticas públicas voltadas para a inovação, valorização, desenvolvimento e sustentabilidade das práticas tradicionais

Atribuir aos produtos cerâmicos artesanais

maranhenses uma clara identidade baseada nos lugares onde são produzidos. Catalogar as memórias dos grupos e comunidades artesanais, resgatar as técnicas, processos e estilos que existiram como práticas comuns aos ancestrais dos povoados maranhenses. Elaborar embalagens adequadas, selos de origem, rótulos ou etiquetas que contextualizam o produto cerâmico e apresentem a sua história
IE3/IE4/IE5/IE

$6 / \mathrm{IT} 1 / \mathrm{IT} 2 / \mathrm{IT} 3$

IE5/IT1/IT2/IT

3

IE5/IT1/IT2/IT

IE6/IE7/IT2/IT

$5 /$ IT6

Fonte: Autoria própria baseado em Cestari (2014) e Ribeiro (2014).

A partir do estudo das características da cadeia produtiva do babaçu no município de Itapecuru Mirim - MA, foi possível organizar um conjunto de diretrizes de projeto específicas para valorizar a cadeia produtiva do babaçu maranhense (DP3), conforme o Tabela 4.

Tabela 4 - Diretrizes para a valorização da cadeia produtiva do babaçu maranhense (DP3)

Diretriz Descricão
Indicadores relacionados

Promover a gestão Desenvolver sistemas e ferramentas para IE4/IE5/IT3

participativa nas aumentar a interação e a troca de

associações e informações entre os trabalhadores, a

cooperativas locais comunidade e as organizações locais

Organizar redes de Desenvolver sistemas e ferramentas para IE3/IE5/IE8/I empresas compartilhar recursos, informações T3 gerenciais e comerciais entre as organizações locais

Fortalecer as redes Desenvolver sistemas e ferramentas para a IE4/IE5/IE6/I de conhecimento difusão dos conhecimentos na cadeia E7/IT3 produtiva 
Promover alternativas intrinsecamente sustentáveis

Desenvolver produtos, serviços, sistemas e IE1/IE2/IT1/I ferramentas que melhorem, aperfeiçoem T2 ou substituam os processos de beneficiamento, armazenamento, transporte, identificação e comunicação dos produtos derivados do babaçu

Diversificar

os Agregar valor aos produtos derivados do IE7/IT6 produtos derivados babaçu de forma a aumentar o valor do babaçu econômico dos produtos beneficiados em comparação com o produto in natura

Diferenciar os Utilizar os valores territoriais locais como produtos IE6/IE7/IT5/ processos através babaçu da cultura das comunidades Desenvolver identidades visuais para os produtos

Destacar os principais elementos de IE6/IE7/IT5/IT identificação do território através de elementos visuais

derivados do babaçu maranhense Certificar os produtos oriundos do babaçu maranhense

IE6/IE7/IE8/IT criação de selos, indicações geográficas e $2 /$ IT7 marcas coletivas que evidenciem as práticas sustentáveis utilizadas pelos produtos derivados do babaçu

Fonte: Autoria própria baseado em Viegas (2015).

Com base no estudo das características e potencialidades do buriti maranhense, foi possível organizar um conjunto de diretrizes de projeto específicas para valorizar a produção artesanal com o buriti no Maranhão (DP4), conforme o Tabela 5.

Tabela 5 - Diretrizes para a valorização da produção artesanal com o buriti no Maranhão (DP4)

\begin{tabular}{lll}
\multicolumn{1}{c}{ Diretriz } & \multicolumn{1}{c}{$\begin{array}{c}\text { Descrição } \\
\text { Identificar as }\end{array}$} & $\begin{array}{l}\text { Indicadores } \\
\text { relacionados }\end{array}$ \\
$\begin{array}{ll}\text { potencialidades do } \\
\text { trabalho artesanal } \\
\text { com o buriti }\end{array}$ & $\begin{array}{l}\text { artesãos e sobre as condições para o } \\
\text { desenvolvimento das atividades artesanais }\end{array}$ & 2 \\
$\begin{array}{ll}\text { Identificar os atributos } \\
\text { do trabalho e do }\end{array}$ & $\begin{array}{l}\text { Identificar os atributos intangíveis que cercam o } \\
\text { trabalho artesanal, para que se possa abordá-los }\end{array}$ & IE6/IE7IE8//IT \\
$\begin{array}{l}\text { produto artesanal } \\
\text { local }\end{array}$ & $\begin{array}{l}\text { como expressão cultural. Consiste na } \\
\text { identificação dos elementos que reportam o }\end{array}$ \\
& $\begin{array}{l}\text { produto ao seu lugar de origem, seja pelo uso de } \\
\text { materiais e técnicas típicas da região ou pelo uso } \\
\text { de elementos simbólicos que representam o }\end{array}$ & \\
& artesão e o seu legado & \\
Materializar os atributos (intangíveis) locais nos & IE6/IE7/IT1 \\
identificados nos & produtos visando a diversificação da produção e & \\
produtos & a geração de renda &
\end{tabular}


Identificar novas

Definir diretrizes para a produção e comercialização dos produtos artesanais Promover ações de mobilização locais matérias-primas

Novas matérias-primas ou novas tecnologias

IE8/IT2 possíveis de serem empregadas ou que corrijam falhas de produção e verificar a viabilidade técnica e econômica para o desenvolvimento de novos produtos

Otimizar os processos, precificar coerentemente

IE8/IT2 os produtos com relação ao tempo e materiais empregados e definir os meios de comercialização e escoamento da produção Realizar reuniões informativas sobre as possibilidades de trabalhos cooperativos. Identificar os interesses dos artesãos e da viabilidade para implementação de cursos, oficinas e consultorias para o aperfeiçoamento das técnicas e processos produtivos artesanais

Fomentar a Realizar oficinas de criatividade para desenvolver modelos e ajustes na produção visando a diversificação e o aumento da qualidade dos produtos

criatividade

Fonte: Autoria própria baseado em Guimarães (2014).

A partir do estudo das características e potencialidades do Parque Nacional dos Lençóis Maranhenses, foi possível organizar um conjunto de diretrizes de projeto específicas para valorizar o Polo turístico do Parque Nacional dos Lençóis Maranhenses (DP5), conforme o Tabela 6.

Tabela 6 - Diretrizes para a valorização do Polo turístico do Parque Nacional dos Lençóis Maranhenses (DP5)

\begin{tabular}{|c|c|c|}
\hline Diretriz & Descrição & $\begin{array}{l}\text { Indicadores } \\
\text { relacionados }\end{array}$ \\
\hline $\begin{array}{l}\text { Desenvolver e promover } \\
\text { produtos e serviços } \\
\text { turísticos a partir do } \\
\text { patrimônio natural local }\end{array}$ & $\begin{array}{l}\text { Envolver as populações locais, os setores } \\
\text { produtivos e as lideranças comunitárias em } \\
\text { iniciativas de implementação de alternativas } \\
\text { produtivas rentáveis e de menor impacto } \\
\text { ambiental }\end{array}$ & $\begin{array}{l}\text { IE4/IE5/IE8/IT } \\
\text { 1/IT2/IT4 }\end{array}$ \\
\hline $\begin{array}{l}\text { Apoiar atividades } \\
\text { econômicas relacionadas } \\
\text { ao ecoturismo local }\end{array}$ & $\begin{array}{l}\text { Desenvolver produtos, serviços, } \\
\text { infraestruturas e comunicação relacionados } \\
\text { com as atividades de ecoturismo para as } \\
\text { comunidades lindeiras }\end{array}$ & $\begin{array}{l}\text { IE5/IE6/IT2/IT } \\
\text { 5/IT6 }\end{array}$ \\
\hline $\begin{array}{l}\text { Desenvolver e promover } \\
\text { infra estruturas que } \\
\text { viabilizem a formação de } \\
\text { Arranjos Produtivos } \\
\text { Locais (APLs) }\end{array}$ & $\begin{array}{l}\text { Fomentar o trabalho cooperativo entre as } \\
\text { micro e pequenas empresas em torno dos } \\
\text { atrativos turísticos, incentivando a formação } \\
\text { de APLs que englobam a soma dos serviços } \\
\text { consumidos pelo turista durante sua estada } \\
\text { no destino }\end{array}$ & $\begin{array}{l}\text { IE3/IE5/IE8/IT } \\
\text { 2/IT3/IT4 }\end{array}$ \\
\hline
\end{tabular}

Fonte: Autoria própria baseado em Trevisan (2006) e Oliveira (2009).

Apropriando-se desses indicadores, designers e projetistas podem fundamentar a construção de novas hipóteses de projeto orientadas para a transformação das atividades produtivas locais rumo a um modelo, ao mesmo 
tempo, mais competitivo e sustentável. Outra característica relevante que tais indicadores possuem é que sinalizam campos para o fomento da inovação, principalmente, nas áreas organizacional, de processos, de produtos, de serviços e de comunicação.

\section{CONSIDERAÇÕES FINAIS}

Como resposta aos objetivos definidos neste trabalho, foram propostos indicadores de design sustentável fundamentados e descritos a partir de princípios estratégicos que permitem o planejamento e a execução de ações de design, comunicação e gestão de negócios com as quais administradores públicos, empreendedores e projetistas podem estabelecer agendas e planos de desenvolvimento a partir da valorização dos recursos presentes no território.

Outrossim, em relação à cadeia produtiva do babaçu maranhense, aos produtos artesanais feitos com o buriti no Maranhão, à cerâmica artesanal maranhense e aos serviços turísticos relacionados com o patrimônio histórico, cultural e natural do Maranhão, foram estabelecidas diretrizes que possibilitam adequar o desenvolvimento de novos produtos, serviços e infra-estruturas às exigências e características regionais, preservando a coerência das proposições projetuais com as estratégias do design sustentável.

Considerando uma visão panorâmica, os resultados obtidos por este trabalho visam fomentar o empreendedorismo local e auxiliar os designers que atuam no Maranhão na compreensão do papel da profissão no contexto regional onde estão inseridos.

Quanto a continuidade deste trabalho e as recomendações para pesquisas futuras, sugere-se a identificação, o mapeamento e o levantamento das correlações para o uso estratégico dos seguintes recursos relevantes para a economia maranhense: Açaí (Euterpe oleracea); Carnaúba (Copernicia prunifera); Jaborandi (Pilocarpus jaborandi); Caju (Anacardium occidentale); Tucum (Bactris setosa); Mamona (Ricinus communis); recursos pesqueiros; e produtos têxteis.

Por fim, a discussão promovida por este trabalho convida os designers a proporem projetos focados nos recursos naturais e nas tradições culturais dos territórios onde estão inseridos, preenchendo as demandas e levando o design a colaborar para o desenvolvimento local e sustentável. 


\title{
Sustainable design indicators for the valorization of the historic, cultural and natural heritage of the state of Maranhão, Brazil
}

\begin{abstract}
Based on narrative bibliographical surveys, on documentary research and through the direct observation, this text presents the results from the research on design strategies and indicators for the valorization of the local resources and products in the territory of Maranhão. The research aimed to promote the competitiveness and sustainability of productive activities in Maranhão through the valorization of the local heritage under the point of view of sustainable design. Therefore, this review reflects the premise that the sustainable use of local resources can improve the quality of life of a large portion of the population involved in the extraction, family farming, the production of typical products and tourism in Maranhão. As a result, here we intend to establish design indicators for the valorization of babassu production chain, of the artisanal production from buriti, from handmade pottery and, indeed, from the historic and natural heritage of the state of Maranhão, Brazil.

KEYWORDS: Sustainable design. Strategic design. Valorization of the local heritage.
\end{abstract}




\section{REFERÊNCIAS}

BISTAGNINO, L. Design Sistemico. Progettare la sostenibilità produttiva e ambientale. Bra: Slow Food Editore, 2009.

CARRAZZA, L. R.; SILVA, M. L. D.; ÁVILA, J. C. C. Manual Tecnológico de Aproveitamento Integral do Fruto do Babaçu. Brasília - DF: Instituto Sociedade, População e Natureza, 2012.

CESTARI, G. A. V. Cerâmica do quilombo de Itamatatiua: Interações do design com o artesanato voltadas à sustentabilidade. 2014. 190 f. Dissertação (Mestrado em Design) - Programa de Pós-graduação em Design, Universidade Federal do Maranhão, São Luís, 2014.

DE GIORGI, C.; GERMAK, C. (Org.). Manufatto. ArtigianatoComunitàDesign. Milão: Silvana Editoriale, 2008.

DESER - Departamento de Estudos Sócio-econômicos rurais. A cadeia produtiva do babaçu: estudo exploratório. Monitoramento da Conjuntura de Mercado das Principais Cadeias Produtivas Brasileiras. Curitiba: Secretaria de Agricultura Familiar/MDA, 2007.

FRAZÃO, J. M. F. Projeto quebra coco: alternativas econômicas para a agricultura familiar assentadas em áreas de ecossistemas de babaçuais. EMBRAPA. São Luís. 2002.

GIL, A. C. Como elaborar projetos de pesquisa. 4a. ed. São Paulo: Atlas, 2002. . Métodos e técnicas de pesquisa social. 6a. ed. São Paulo: Atlas, 2008.

GUIMARÃES, M. J. S. Contribuições do Design para o Desenvolvimento Sustentável da Produção Artesanal. 2014. 139 f. Dissertação (Mestrado em Design) - Programa de Pós-graduação em Design, Universidade Federal do Maranhão, São Luís, 2014.

IBGE - Instituto Brasileiro de Geografia e Estatística. Produção da extração vegetal e da silvicultura 2011. Rio de Janeiro, v.26, n. 2, 2012.

KRUCKEN, L. Design e Território: valorização de identidades e produtos locais. São Paulo: Studio Nobel, 2009.

MANZINI, E. Design para a inovação social e sustentabilidade: Comunidades criativas, organizações colaborativas e novas redes projetuais. Rio de Janeiro: Epapers, 2008.

MANZINI, E.; VEZZOLI, C. O Desenvolvimento de Produtos Sustentáveis: Os requisitos ambientais dos produtos industriais. 1a ed., 2a reimpressão. São Paulo: Editora da Universidade de São Paulo, 2008.

MARTINS, E. M. Desenvolvimento local e atividade turística em Barreirinhas - 
Cidade Portal dos Lençóis Maranhenses. 2008. 130 f. Dissertação (Mestrado em Geografia Meio Ambiente e Desenvolvimento) - Programa de Pós-graduação em Geografia Meio Ambiente e Desenvolvimento, Universidade Estadual de Londrina, Londrina, 2008.

MMA - Ministério do Meio Ambiente. Promoção Nacional da Cadeia de Valor do Coco Babaçu. Brasília - DF: Ministério do Meio Ambiente, 2009.

MOZOTA, B. B. et al. Gestão do design: usando o design para construir valor de marca e inovação corporativa. Porto alegre: Bookman, 2011.

OLIVEIRA, J. A. P. (Org.). Pequenas empresas, arranjos produtivos locais e sustentabilidade. Rio de Janeiro: Editora FGV, 2009.

PARENTE, M. II design per la valorizzazione territoriale. II caso del Rione Sanità a Napoli. Tafterjournal, n. 22, abr. 2010. Disponível em: <Erro! A referência de hiperlink não é válida.>. Acesso em: 12 mai. 2016.

PINTO, A. et al. Boas práticas para manejo florestal e agroindustrial de produtos florestais não madeireiros: açaí, andiroba, babaçu, castanha-do-brasil, copaíba e unha-de-gato. Belém/Manaus: IMAZON/SEBRAE-AM, 2010.

PORTO, M. J. F. Estudo Preliminar de Dispositivo de Quebra e Caracterização dos Parâmetros Físicos do Coco Babaçu. Campinas: UNICAMP, 2004.

RIBEIRO, I. C. B. Estratégias de Design Sustentável para a construção de identidades Terroir no Maranhão. 2014. 191 f. Dissertação (Mestrado em Design) - Programa de Pós-graduação em Design, Universidade Federal do Maranhão, São Luís, 2014.

SANTOS, A. et al. Proposition of criteria for the economical dimension of Design for Sustainability. III International Symposium on Sustainable Design, 2011, Recife. Anais..., 2011.

SOUZA, P. F. A. Sustentabilidade e responsabilidade social no design do produto: rumo à definição de indicadores. 2007. 294 f. Tese (Doutorado em Arquitetura e Urbanismo) - Faculdade de Arquitetura e Urbanismo, Universidade de São Paulo, São Paulo, 2007.

SOUZA, V. S. Olhares cruzados: o Centro Histórico de São Luís sob a lente dos atores turísticos. 2014. 166 f. Dissertação (Mestrado em Turismo e Hotelaria) Programa de Pós-graduação em Turismo e Hotelaria, Universidade do Vale do Itajaí, Balneário Camboriú, 2014.

THACKARA, J. In the bubble. Design per un futuro sostenibile. Turim: Umberto Allemandi \& C. , 2008.

TREVISAN, S. D. P. (Org.). Comunidades sustentáveis: a partir do turismo com base local. Ilhéus: Editus, 2006. 
VEZZOLI, C. Design de Sistemas para a Sustentabilidade. Teorias, métodos e ferramentas para o design sustentável de sistemas de satisfação. Salvador: EDUFBA, 2010.

VIEGAS, V. A. Estratégias de Design Sustentável para a valorização dos recursos locais a partir do estudo da cadeia do babaçu no município de Itapecuru Mirim. 2015. 134 f. Dissertação (Mestrado em Design) - Programa de Pós-graduação em Design, Universidade Federal do Maranhão, São Luís, 2015.

VOSGERAU, D.S.A.R.; ROMANOWSKI, J. P. Estudos de revisão: implicações conceituais e metodológicas. Diálogo Educacional, Curitiba, v. 14, n. 41, p. 165189, jan./abr. 2014. crossref

LUCCA, A. S. Indicadores de design sustentável para a valorização do patrimônio histórico, cultural e natural do Maranhão. R. Gest. Industr., Ponta Grossa, v. 14, n. 1, p. 138-159, jan./mar. 2018.

Disponível em: <https://periodicos.utfpr.edu.br/rgi>. Acesso em: XXX

Correspondência:

André de Souza Lucca

Av. Sete de Setembro, 3165, Rebouças, Curitiba, Paraná, Brasil.

Direito autoral: Este artigo está licenciado sob os termos da Licença Creative Commons-Atribuição 4.0 Internacional. 